\title{
Persic Oil
}

National Cancer Institute

\section{Source}

National Cancer Institute. Persic Oil. NCI Thesaurus. Code C66359.

A pale-yellow to red fatty oil; soluble in ether, chloroform, and carbon disulfide; taste and aroma are similar to almond oil; the oil is expressed from blanched seeds of peaches or apricots; used as a flavoring, in medicine, and as a nutrient similar to olive and almond oils. (online dictionary) 